\title{
Promoting career growth potential: political skill, the acquisition of social resources and ingratiation
}

\author{
Hataya Sibunruang $^{1}$ (D) and Norifumi Kawai ${ }^{2}$ \\ ${ }^{1}$ Waikato Management School, University of Waikato, Gate 7, Hillcrest Road, Hamilton 3240, New Zealand and ${ }^{2}$ Faculty of \\ Economics, Sophia University, Building 2-926, 7-1 Kioi-cho, Chiyoda-ku, Tokyo, 102-8554, Japan \\ Author for correspondence: Hataya Sibunruang, E-mail: hataya.sibunruang@waikato.ac.nz
}

(Received 15 July 2020; revised 20 April 2021; accepted 22 May 2021; first published online 30 June 2021)

\begin{abstract}
Informed by social resources theory, we provide an explanation for how political skill enables employees' access to social resources, notably expressive network resources and developmental feedback granted by supervisors, thereby enhancing their potential for career growth. Employees can further leverage the attained resources to maximize their chances for career growth by exercising ingratiation toward their supervisors. Data from 399 independently matched subordinate-supervisor dyads in Japan partially support our predictions. While supervisor-focused expressive network resources and supervisor developmental feedback account for mediating mechanisms through which political skill could predict career growth potential, the use of ingratiation to further leverage these social resources is rather deemed insignificant. Theoretical and practical implications of the findings are discussed.
\end{abstract}

Key words: Career growth potential; expressive network resources; ingratiation; political skill; supervisor developmental feedback

Employees seek to remain with organizations that offer career growth opportunities (Weng, McElroy, Morrow, \& Liu, 2010). However, the traditional perspective that knowledge and hard work inevitably lead to career growth may not serve as the only explanation (Blickle, Schneider, Liu, \& Ferris, 2011), as recent empirical evidence has revealed other potential factors, such as political savvy and networking (Cullen, Gerbasi, \& Chrobot-Mason, 2018; Ren \& Chadee, 2017; Spurk, Kauffeld, Barthauer, \& Heinemann, 2015). For instance, employees high in political skill tend to view connections formed with other organizational members as opportunities to capitalize on (McAllister, Ellen, \& Ferris, 2018). Subsequently, they proactively engage in building relationships with others, especially their supervisors and other higher-ups, as these connections allow for greater access to valuable resources, such as job information, professional advice, and emotional support, thereby equipping individuals with capabilities for growth (Wei, Liu, Chen, $\& \mathrm{Wu}, 2010$ ). Indeed, politically skilled individuals possess a distinct interpersonal capability that enables them to present their behaviors in ways that inspire trust and goodwill, leading to favorable interpersonal relationships (Epitropaki et al., 2016). Drawing upon social resources theory (Lin, Ensel, \& Vaughn, 1981), this study considers political skill (Ferris et al., 2007) as an important interpersonal competency that employees can use to enhance their career growth potential, which is determined by a supervisor's assessment of the employee's readiness to achieve career growth opportunities (e.g., job enrichment, promotions, training and development, etc.). Through relationship building, politically skilled employees are able to form connections with 
their supervisors who can grant them access to the necessary resources for career advancement. Political skill consistently proved to be a significant predictor of career-related benefits, including perceived employability, promotability ratings, and actual promotions (Blickle et al., 2011; Chiesa, Van der Heijden, Mazzetti, Mariani, \& Guglielmi, 2020; Todd, Harris, Harris, \& Wheeler, 2009).

This study is conducted in the context of Japanese careers, which have experienced drastic changes since the collapse of the 'bubble' economy in the late 1990s. Typical Japanese companies highly emphasize lifelong employment in exchange for employees' lifetime commitment (Dore, 1973). However, due to current business environment dynamics, organizations can no longer guarantee such support for their workers. Under these new circumstances, many employees in Japan have since realized that they must take control of and manage their own careers (Kuroda \& Yamamoto, 2005; Taniguchi, Kato, \& Suzuki, 2006). Similarly, we recognize that employees are not passive recipients of their work environments but rather active individuals who can improve their work circumstances and thus, exert agency over their career course (King, 2004). Specifically, we suggest that employees can utilize their interpersonal competency, notably political skill, to navigate work, and place themselves in stronger positions to attain career growth. Further informed by the Japanese work culture, which can be generally regarded as highly collectivistic and showing high uncertainty avoidance (Hofstede, 1984), we emphasize relationship building as an instrumental factor in achieving career growth. In a highly collectivistic work culture, people participate in informal groups and engage in interpersonal relationships. In a high-uncertainty avoidance culture, people tend to feel uncomfortable within ambiguous situations and seek to find ways in which they can become more informed about their surroundings (Hofstede, 2001). In this regard, it is reasonable to see employees building relationships with more senior staff, such as their supervisors, as they can help provide important information about an organization's context (Bozionelos, 2006). Due to their adaptable and delicate interpersonal capabilities (Ferris et al., 2007), employees high in political skill can effectively form strong connections with their supervisors, who serve as gatekeepers to information and resources, some of which are essential in promoting their career growth potential (King, 2004; Wei et al., 2010; Wei, Chiang, \& Wu, 2012).

Given that the key skillset and career context of interest are within the interpersonal domain, we consider two types of resources that employees can interpersonally source from their supervisors. First, supervisor-focused expressive network resources consist of strong interpersonal relationships that employees form with their supervisors, which further provide friendship, emotional support, confirmation, and feedback on work-related issues (Fombrun, 1982; Krackhardt, 1992). Our argument is that such emotionally supportive relationships are essential in promoting one's career growth in a highly collectivistic work culture such as Japan, as they emphasize relationship building and informal connections. Second, supervisor developmental feedback contains information related to in-role expectations, extra-role expectations and cultural norms, all of which aim toward the long-term development of employees (George \& Zhou, 2007; Li, Harris, Boswell, \& Xie, 2011). Such information is highly valuable in a high-uncertainty avoidance work culture such as Japan, as it helps reduce uncertainty that employees may have toward organizational context. Importantly, due to the future orientation of developmental feedback (Zhou, 2003), we argue that this information is important in achieving longer-term career outcomes, such as career growth.

While many studies have endeavored to examine the benefits of overall social resources (Bozionelos, 2003; Wolff \& Moser, 2009), there are still mixed results concerning their instrumentality in achieving career objectives (Bozionelos \& Wang, 2006; Seibert, Kraimer, \& Liden, 2001). Therefore, the mere existence of resources may not sufficiently explicate the link between political skill and career growth potential. Our argument is that individuals can differ in the extent to which they will combine, utilize, and leverage the social resources obtained from having exercised their political skill to increase their chances for career growth. Specifically, we suggest that employees can place themselves in even stronger positions if they take advantage of the attained expressive network resources and developmental feedback by executing strategic, goaldirected influence tactics, such as ingratiation, which is described as an attempt to enhance 


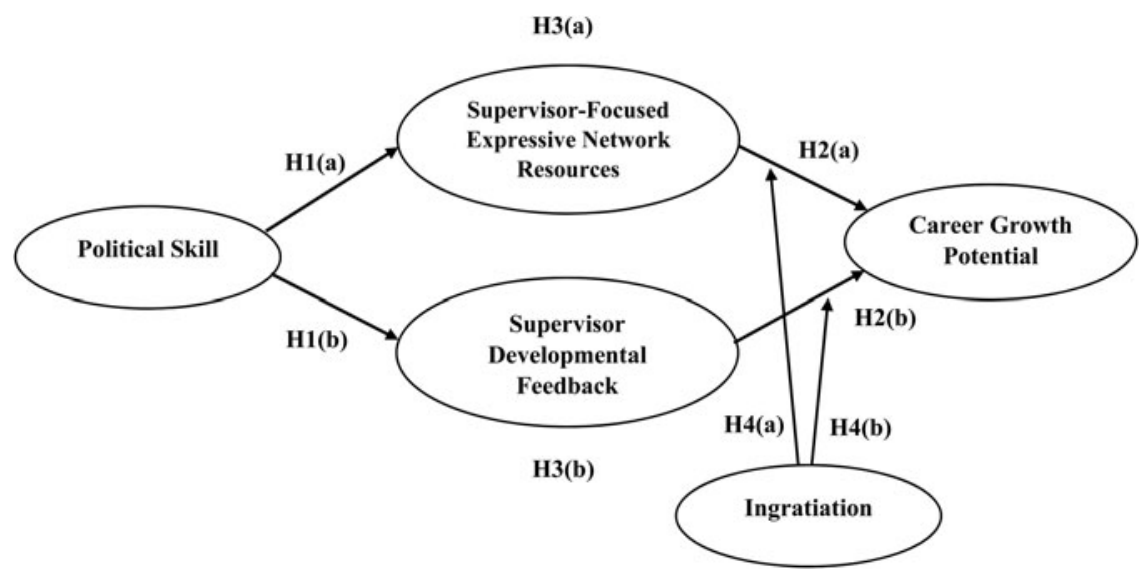

Figure 1. The proposed research model.

one's interpersonal attractiveness and gain favors from another person (Kumar \& Beyerlein, 1991). Given the interpersonal focus of ingratiation (Liden \& Mitchell, 1988), this strategy is essential in enabling employees to navigate through the informal connections that they have formed with their supervisors, further allowing them to tailor the use of their resources to lead to career growth. Strong empirical evidence supports the instrumental role of ingratiation in attaining career-related benefits (Sibunruang, Garcia, \& Tolentino, 2016; Wu, Kwan, Wei, \& Liu, 2013).

Ultimately, this study aims to address ' $w$ hy do some employees experience more successful career growth?' We do so by using social resources theory (Lin et al., 1981) as an overarching theoretical perspective to provide an integrated understanding of how interpersonal competency (i.e., political skill), social resources (i.e., expressive network resources and developmental feedback from supervisors), and interpersonal influence behaviors (i.e., ingratiation) merge to promote employee career growth potential (see Figure 1). In doing so, we contribute to the career growth literature in the following ways. First, our proposed research model is informed by the current career circumstances facing Japanese employees and some of the dominant features of their cultural work context. Weng \& Zhu (2020) noted in their review paper that research on career growth should take a more context-specific approach, because the notion of careers involves an interplay between individual employees, organizations, and society. Therefore, career growth is inevitably influenced by the surrounding contexts and situations in which it occurs. Second, this study provides insights into some of the unexplored mechanisms that may unpack the benefits of political skill on career growth. For instance, in promoting career interests, past research has largely emphasized the significance of instrumental network resources (e.g., Blommaert, Meuleman, Leenheer, \& Butkēviča, 2020; Bozionelos, 2003; Peng \& Luo, 2000; Seibert, Sargent, Kraimer, \& Kiazad, 2017), which enable exposure to top management as well as access to job-related information and professional advice, while little is known about the potential of expressive network resources. Our argument is that expressive resources provide psychosocial support via a close friendship, which not only fosters trust but also facilitates the exchange of valued resources (Brass, 1984). In fact, trust is a key component of sharing and exchanging benefits among individuals in a relationship (Bradach \& Eccles, 1989). Finally, we recognize supervisor developmental feedback as another critical aspect in advancing one's career. While research has thus far determined the behavioral outcomes of developmental feedback, such as task performance, helping behaviors, and creativity (Li et al., 2011; Zhou, 2003), the future-oriented nature of this feedback should be particularly essential in directing employees' attention and motivation toward long-term outcomes, such as career growth. In sum, our study aims to address 
this limited attention on the instrumentality of both expressive network resources and developmental feedback from supervisors in achieving career objectives.

\section{Theory and development of hypotheses}

Popular advice for getting ahead in one's career never fails to mention relationship building and networking, especially with important people who can bring them closer to their career objectives (Blickle et al., 2011; Perrewe \& Nelson, 2004; Todd et al., 2009). For this reason, some employees are highly active in forming connections with more senior staff, such as their supervisors, to gain access to information and win social support in the organization (Cullen et al., 2018; Yang, Liu, Wang, \& Zhang, 2020). According to social resources theory (Lin et al., 1981), access to social resources is instrumental to achieving personal objectives. More specifically, the theory encompasses two key components, notably, (a) social relations and (b) resources embedded in these social relations. First, the theory advocates the relevance of connecting with those at higher levels of the management hierarchy. Due to their position, these people generally have greater access to and control over information, resources, and rewards. Following this line of argument, we argue that employees high in political skill are better able to form valuable connections with their immediate supervisors, thereby allowing them greater access to the resources needed to advance in their career (McAllister et al., 2018; Wei et al., 2010, 2012). In addition to relationship building, the theory further focuses on the nature of resources embedded in these social networks. In other words, it is also important to consider the type of resources required for individuals to reach their personal career objectives (Seibert et al., 2001). In this study, we consider the strategic functions that supervisor-focused expressive network resources and supervisor developmental feedback may serve in enabling politically skilled employees to enhance their career growth potential.

\section{Political skill and the acquisition of social resources}

Resource acquisition is the result of relationship building and informal connections formed among individuals in a particular social network (Seibert et al., 2001). Guided by social resources theory (Lin et al., 1981), 'social resources are embedded in the positions of contacts an individual reaches through his social network' (p. 395). The theory specifically highlights connections formed with those at higher levels of the management structure, such as supervisors, managers, and other higher-ups. Due to their positional power, these people have more control over the distribution of many valuable resources (Lin et al., 1981). When individuals are well positioned in these networks, their ability to garner, utilize, and leverage the available resources figures prominently (Wei et al., 2010, 2012). Therefore, one's ability to engage in interpersonal relationships is important in acquiring social resources, such as expressive network resources and developmental feedback (Fang, Chi, Chen, \& Baron, 2015). For instance, employees who possess political skill have an astute understanding of their social environment and know how to use this understanding to build relationships with others (Ferris et al., 2005, 2007). Due to positive and successful experiences in past encounters, research has revealed that politically skilled employees derive a greater sense of personal security and self-confidence that they can successfully gain positive responses from engaging in interpersonal interactions with others (Munyon, Summers, Thompson, \& Ferris, 2015). As a result, employees high in political skill actively build social networks at work, as they view relationships as opportunities that they can exploit for future gain (McAllister et al., 2018; Perrewé, Ferris, Frink, \& Anthony, 2000).

Individuals who are high in political skill display four important characteristics. First, due to their quality of being socially astute, politically skilled employees have an accurate understanding of other people's motivations and behaviors, which helps them identify the correct way to interact with others (Ferris et al., 2005, 2007). Furthermore, due to their networking ability, politically skilled employees are adept at identifying relevant contacts who could help them create 
opportunities, such as their supervisors, and are also effective in building social networks as well as positioning themselves within these networks (Ferris et al., 2007; McAllister et al., 2018). Networking is a dyadic interpersonal process that involves generating social capital, goodwill, and trust between members within a social network (Porter \& Woo, 2015). Political skill also consists of specific action-oriented capabilities. For instance, interpersonal influence represents one's ability to adapt his or her behavior to different social contexts, which allows employees to make the right impression in front of their supervisors and build a good rapport. Finally, apparent sincerity represents one's ability to behave in a manner that appears authentic, genuine, and sincere, which can help an employee hide their ulterior motives and instead instill trust in their supervisors (Ferris et al., 2005, 2007). Trust is a critical factor that facilitates the exchange of valuable resources among individuals (Bradach \& Eccles, 1989).

Therefore, politically skilled employees are well equipped with specific interpersonal abilities that enable them to develop favorable interpersonal relationships with their supervisors and, as a result, gain access to social resources, including supervisor-focused expressive network resources as well as supervisor developmental feedback.

Hypothesis 1: Political skill is positively associated with (a) supervisor-focused expressive network resources and (b) supervisor developmental feedback.

\section{Social resources and career growth potential}

The social resources acquired from having utilized political skill are instrumental in achieving career growth. Further informed by social resources theory (Lin et al., 1981), once relationships with key gatekeepers (e.g., immediate supervisors) who control the distribution of certain resources have been formed, the extent to which individuals will successfully achieve their career objectives also depends on the nature of the resources embedded in these social ties. Similarly, we assert that supervisor-focused expressive network resources and supervisor developmental feedback are essential in promoting employee career growth potential, especially when accounting for the dominant features of the Japanese work culture (Hofstede, 1984). First, Japanese work culture is regarded as highly collectivistic; people within the culture strongly value group membership and group harmony (Leung, Au, Fernández-Dols, \& Iwawaki, 1992). For this reason, participation in informal groups and engagement in interpersonal relationships (Hofstede, 2001) are deemed appropriate in such a cultural setting, and these actions are more likely to be an effective way for employees to work toward their career growth (Bozionelos, 2006). Indeed, expressive network resources denote strong interpersonal relationships formed among organizational members, which further provide emotional support, confirmation, feedback on work-related issues, and certain types of information (Ibarra, 1993; Krackhardt, 1992). Japanese work culture can be further described as having high uncertainty avoidance (Hofstede, 1984). In other words, people tend to feel uncomfortable in uncertain situations and will seek to minimize such ambiguity in their surroundings. Hence, it is reasonable to expect that employees in this cultural setting are inclined to seek relationships with more senior members, such as their supervisors, as such relationships could help reduce uncertainty by providing important information about the organization's environment (Bozionelos, 2006). This information can be disseminated in a form of supervisor developmental feedback, which reflects the extent to which supervisors provide helpful and valuable information that enables employees to improve their work and broader aspects of their work life (Li et al., 2011).

Supervisor-focused expressive network resources denote closely tied connections formed between employees and supervisors (Bozionelos, 2006). Such favorable interpersonal relationships are likely to offer more fine-grained information that is essential in achieving personal objectives, facilitate rapid feedback exchange concerning work-related issues, and allow access to a greater amount of support. These outcomes are largely due to mutual trust shared among 
closely connected members (Bradach \& Eccles, 1989). Subsequently, timely access to as well as the quantity and quality of the benefits obtained from supervisor-focused expressive resources should help enhance individuals' work performance and effectiveness, making them ready for career growth (Seibert et al., 2001). Indeed, the extent to which supervisors and managers allocate career growth opportunities depends on their assessment of an employee's performance and competence (Liu, Liu, \& Wu, 2010). Furthermore, considering the affective perspective, when supervisors assess their employees' capabilities and potential for career growth, their assessment can be easily influenced by their subjective feelings developed toward a stimulus object, notably a focal employee (Feldman, 1981; Ferris \& Judge, 1991). Specifically, supervisors are more likely to favorably rate employees with whom they share close connections.

Supervisor developmental feedback can be described as 'the extent to which supervisors provide their employees with helpful or valuable information that enables the employees to learn, develop and make improvements on the job' (Zhou, 2003, p. 415). This type of feedback should equip employees for career growth for three major reasons. First, supervisor developmental feedback contains information that communicates relational roles, cultural norms, and extra-role expectations (George \& Zhou, 2007; Zhou, 2003), which enables employees to become well informed of their surrounding work environments. As shown in Li et al. (2011) study, new employees who received more developmental feedback from their coworkers and supervisors managed to transition into the new workplace more easily and subsequently exhibited higher performance levels during the socialization period compared to those who received less developmental feedback. Following these lines of argument, we argue that employees require such information to navigate work, thrive in their organizations, and pave their way toward career growth. Second, developmental feedback contains behaviorally relevant information that aims to improve one's performance at work (Zhou, 2003). Hence, the provided feedback is highly specific in terms of directions and specific actions that employees can take to make overall work improvements. Accordingly, supervisor developmental feedback is reported as a significant predictor of important work outcomes, such as task performance and creative performance (Li et al., 2011; Zhou, 2003). The more positive a supervisor's assessment of an employee's performance potential, the greater the allocation of career growth opportunities (Liu et al., 2010). Importantly, developmental feedback has a future orientation, which will likely direct employees' attention and motivation toward achieving long-term goals, such as career growth. While research on the impact of supervisor developmental feedback on long-term career outcomes is rather scant, there is empirical support for how developmental feedback may promote a longerterm outlook for employees toward their employer (e.g., higher organizational commitment and lower turnover intention; Joo \& Park, 2010).

Building on the aforementioned arguments, we predict that the greater the access employees have to social resources, notably expressive network resources and developmental feedback from supervisors, the higher their chances and potential for attaining career growth.

Hypothesis 2(a): Supervisor-focused expressive network resources are positively associated with career growth potential.

Hypothesis 2(b): Supervisor developmental feedback is positively associated with career growth potential.

In sum, social resources theory (Lin et al., 1981) posits two key factors that lead to the achievement of career objectives, including relationship building and resources embedded in the relationship developed. Guided by this theoretical perspective, our argument is that employees high in political skill are in a strong position to obtain expressive network resources and developmental feedback granted by their supervisors. Through active networking and their ability to be convincing, these employees are able to form favorable relationships with their supervisors and, 
therefore, are better able to secure the support, feedback, and information needed for career growth (Wei et al., 2010, 2012). Combining the above two predictions (i.e., Hypotheses 1 and 2), we expect that supervisor-focused expressive network resources and supervisor developmental feedback will account for mediating mechanisms through which politically skilled employees can enhance their career growth potential.

Hypothesis 3(a): Supervisor-focused expressive network resources mediate the relationship between political skill and career growth potential.

Hypothesis 3(b): Supervisor developmental feedback mediates the relationship between political skill and career growth potential.

\section{The moderating role of ingratiation}

While expressive network resources and developmental feedback provided by supervisors can potentially promote employee career growth potential, these resources can be further leveraged toward optimizing an individual's chances for career growth. For instance, employees can exercise goal-directed, strategic influence behaviors, such as ingratiation, toward their immediate supervisors. Ingratiation is a set of interpersonal behaviors that attempt to increase one's interpersonal attractiveness and ultimately gain favors from another individual (Kumar \& Beyerlein, 1991; Westphal \& Stern, 2007). Examples of ingratiation include giving compliments, showing agreement with another person's opinions, and doing favors for someone (Higgins \& Judge, 2004; Kumar \& Beyerlein, 1991). Overall, ingratiation has been demonstrated to result in numerous positive outcomes, including positive performance ratings, career success, and increased chances for board appointments (Aryee, Wyatt, \& Stone, 1996; Sibunruang et al., 2016; Westphal \& Shani, 2016).

This strategy plays an important role in three important ways. First, due to the interpersonal focus of ingratiation (Liden \& Mitchell, 1988), this strategy is essential in enabling employees to maintain the strong connections they have formed with their supervisors. Both supervisorfocused expressive network resources and supervisor developmental feedback can be gained from having developed favorable relationships with supervisors (Bozionelos, 2006). Thus, to maintain these relationships and access to the necessary resources for career growth, interpersonal behaviors such as ingratiation are useful. Second, by exercising ingratiation toward their supervisors, employees can elicit positive affect in their supervisors and subsequently instill trust in them (Heider, 1958). The trust and goodwill generated make it easier for employees to navigate the informal connections formed with their supervisors. In doing so, they can gain even more in-depth insight into their surrounding work environment, including its nature, boundaries and standards, which better informs them how to use the obtained resources to make their way toward career growth. Finally, ingratiation is a goal-directed behavior. One motivation behind exercising ingratiation is achieving personal career goals (Judge \& Bretz, 1994). With this goal in focus, employees can direct their ingratiatory effort and behaviors toward achieving career growth when coupled with using expressive network resources and developmental feedback.

Along these lines of argument, we expect that employees who ingratiate their supervisors more frequently will be better able to maintain their access to the social resources (i.e., supervisorfocused expressive network resources and supervisor developmental feedback) obtained from having utilized their political skill, and further leverage them toward maximizing their chances for career growth. By contrast, if employees exercise ingratiation less frequently, the social resources obtained from their political savvy will be less leveraged toward enhancing their career growth potential. Importantly, while political skill enables access to social resources (i.e., political skill as a predictor), ingratiation enables maintaining and utilizing these resources to achieve career growth (i.e., ingratiation as a second-stage boundary condition). 
Hypothesis 4(a): At the second-stage moderation, the mediating relationship between political skill, supervisor-focused expressive network resources, and career growth potential becomes stronger at high ingratiation levels as opposed to low ingratiation levels.

Hypothesis 4(b): At the second-stage moderation, the mediating relationship between political skill, supervisor developmental feedback, and career growth potential becomes stronger at high ingratiation levels, as opposed to low ingratiation levels.

\section{Methods}

\section{Participants and procedures}

Our research included 900 full-time employees from three large-sized manufacturing companies in Japan. The total sample was further divided into 450 independently matched subordinatesupervisor dyads. The human resources (HR) departments of the participating companies were responsible for administering the self-reported surveys. We instructed HR personnel to distribute a large envelope containing two questionnaires (i.e., subordinate and supervisor questionnaires), both of which were sealed in two separate smaller envelopes, to each participating subordinate. The participating subordinates were then instructed to complete their own questionnaire and give the other sealed envelope to their immediate supervisor. To avoid comparison biases that can potentially arise, a supervisor only assessed one of their subordinates on his/her career growth potential, not more than this. Furthermore, to match dyadic data sources, we adopted a coding system. All participants returned their completed questionnaires directly to the HR department. After we removed questionnaires with mismatched dyads and missing responses, the final sample comprised 399 subordinate-supervisor dyads, representing a valid response rate of $88.7 \%$. Among the focal employees, $72.9 \%$ were male, the average age was 37.27 years, and the average tenure was 17.08 years. Importantly, our participants came from various functional departments (e.g., marketing, quality control, production, human resource, etc.) and across organizational levels (e.g., nonsupervisory employees, line management, middle management, and top management).

\section{Measures}

Unless otherwise indicated, the response format for the following scale items was a 7-point Likert scale, ranging from strongly disagree (1) to strongly agree (7). Given that English is not a native language for the Japanese participants, we adopted the back-translation procedure when developing the questionnaire surveys.

\section{Political skill}

Subordinates reported their political skill using the 18-item scale developed by Ferris et al. (2005). Example items include 'I spend a lot of time and effort at work networking with others' and 'I have good intuition or savvy about how to present myself to others.' In this study, Cronbach's $\alpha$ was .87 .

\section{Supervisor-focused expressive network resources}

Subordinates rated the extent to which expressive network resources were available to them through their relationships with their immediate supervisors using the three-item subscale of network resources measure developed by Bozionelos (2003). Example items include 'I share emotional support, feedback, and work confirmation with my immediate supervisor' and 'I frequently talk to my supervisor about work-related topics.' In this study, Cronbach's $\alpha$ was .75.

\section{Supervisor developmental feedback}

Subordinates also determined the extent to which they received developmental feedback from their supervisors using the three-item scale developed by Zhou (2003). Example items are 
'While giving me feedback, my supervisor focuses on helping me to learn and improve' and 'My supervisor provides me with useful information on how to improve my job performance.' The scale yielded a reliability coefficient of .72 .

\section{Ingratiation}

Subordinates rated how often they exercised ingratiation toward their immediate supervisors on a 7-point Likert scale, ranging from never (1) to very often (7), using the four-item subscale of impression management measure developed by Bolino and Turnley (1999). Sample items are 'I praise my supervisor for their accomplishments, so they consider me a nice person' and 'I do personal favors for my supervisor to show them that I am friendly.' The scale yielded a reliability coefficient of .76 .

\section{Career growth potential}

Supervisors assessed the focal employee's career growth potential using the two-item scale developed by Liu et al. (2010). The two items are 'This employee will attain his or her career goals in this organization' and 'This employee will receive growth and development opportunities in this organization.' Given that supervisors had to determine their employees' achievement of personal career goals, some challenges may arise, as supervisors may not accurately assess employees' career goals. To preempt this issue, we first asked focal employees to indicate their 'career aspirations in the next 5 years' on a separate sheet of paper and instructed them to share this sheet with their supervisors for evaluating the employee's career growth potential. The scale yielded a SpearmanBrown coefficient of .86 .

\section{Control variables}

Following conventions on the research in careers (McClelland, Barker, \& Oh, 2012; Stroh, Brett, \& Reilly, 1992; Thacker \& Wayne, 1995), we controlled for employees' demographic attributes, including age, gender, and organizational tenure, to minimize confounding effects and rule out alternative explanations.

\section{Results}

Descriptive statistics (i.e., means and standard deviations), zero-order correlations, and reliability estimates are presented in Table 1. The key variables of interest all exhibited acceptable reliabilities, with reliability coefficients of at least .70 (Kline, 1999; Nunnally, 1978). In terms of multicollinearity, except for the relationship between age and tenure, both of which are control variables, none of the remaining zero-order correlations exceeded .75.

\section{Hypotheses testing}

First, we proposed that political skill predicted the acquisition of social resources, notably supervisor-focused expressive network resources and supervisor developmental feedback. Using the IBM SPSS statistics 26 to run multiple regression analyses, our results revealed a positive and statistically significant relationship between (a) political skill and expressive network resources $(\beta=.47, p<.01)$ and between (b) political skill and developmental feedback $(\beta=.20$, $p<.01$ ), fully supporting Hypothesis 1 . We further hypothesized that the two social resources would promote career growth potential. Accordingly, our regression results showed a positive and statistically significant relationship between (a) expressive network resources and career growth potential $(\beta=.15, p<.01)$ as well as between $(b)$ developmental feedback and career growth potential $(\beta=.14, p<.05)$, further supporting Hypothesis 2 . These results are shown in Table 2 . 
Table 1. Descriptive statistics, zero-order correlations and reliability estimates

\begin{tabular}{|c|c|c|c|c|c|c|c|c|c|c|}
\hline & Mean & SD & 1 & 2 & 3 & 4 & 5 & 6 & 7 & 8 \\
\hline 1. Gender (subordinate) & .73 & .44 & & & & & & & & \\
\hline 2. Age (subordinate) & 37.26 & 10.64 & $.21^{\star \star}$ & & & & & & & \\
\hline 3. Tenure (subordinate) & 17.08 & 10.67 & $.20^{\star \star}$ & $.95^{\star \star}$ & & & & & & \\
\hline 4. Political skill & 3.94 & .74 & .05 & $-.20^{\star *}$ & $-.21^{\star \star}$ & $(.87)$ & & & & \\
\hline 5. Supervisor-focused expressive network resources & 4.26 & 1.35 & $-.15^{\star \star}$ & $-.22^{\star \star}$ & $-.21^{\star \star}$ & $.48^{\star \star}$ & $(.75)$ & & & \\
\hline 6. Supervisor developmental feedback & 4.36 & 1.09 & $-.17^{\star \star}$ & $-.32^{\star \star}$ & $-.33^{\star \star}$ & $.25^{\star \star}$ & $.26^{\star \star}$ & $(.72)$ & & \\
\hline 7. Ingratiation & 3.14 & 1.03 & .09 & $-.21^{\star \star}$ & $-.18^{\star \star}$ & $.45^{\star \star}$ & $.27^{\star \star}$ & $.24^{\star \star}$ & (.76) & \\
\hline 8. Career growth potential & 4.31 & 1.04 & -.02 & $-.16^{\star \star}$ & $-.18^{\star \star}$ & $.16^{\star \star}$ & $.20^{\star \star}$ & $.20^{\star *}$ & .09 & (.86) \\
\hline
\end{tabular}

Note: $N=399 ;{ }^{*} p<.05,{ }^{* *} p<.01 . \mathrm{SD}=$ standard deviation. 
Table 2. Regression results for supervisor-focused expressive network resources, supervisor developmental feedback, and career growth potential

\begin{tabular}{|c|c|c|c|c|c|c|c|}
\hline & \multicolumn{2}{|c|}{$\begin{array}{l}\text { Supervisor-focused } \\
\text { expressive network } \\
\text { resources }\end{array}$} & \multicolumn{2}{|c|}{$\begin{array}{l}\text { Supervisor } \\
\text { developmental } \\
\text { feedback }\end{array}$} & \multicolumn{3}{|c|}{ Career growth potential } \\
\hline & Step 1 & Step 2 & Step 1 & Step 2 & Step 1 & Step 2 & Step 3 \\
\hline Constant & & & & & $4.45^{\star \star}$ & $4.21^{\star \star}$ & $4.25^{\star *}$ \\
\hline Age & -.21 & -.2 & -.03 & -.03 & .06 & .1 & .09 \\
\hline Gender & $-.11^{\star}$ & $-.15^{\star \star}$ & $-.11^{\star}$ & $-.13^{\star \star}$ & .02 & .05 & .06 \\
\hline Organizational tenure & .02 & .11 & -.28 & -.28 & -.24 & -.21 & -.21 \\
\hline Political skill & & $.47^{\star \star}$ & & $.20^{\star \star}$ & & & \\
\hline $\begin{array}{l}\text { Supervisor-focused } \\
\text { expressive network } \\
\text { resources }\end{array}$ & & & & & & $.15^{\star \star}$ & $.13^{*}$ \\
\hline $\begin{array}{l}\text { Supervisor developmental } \\
\text { feedback }\end{array}$ & & & & & & $.14^{*}$ & $.12^{*}$ \\
\hline Ingratiation & & & & & & -.01 & -.01 \\
\hline $\begin{array}{l}\text { Supervisor-focused } \\
\text { expressive network } \\
\text { resources } \times \text { ingratiation }\end{array}$ & & & & & & & $-.13^{\star}$ \\
\hline $\begin{array}{l}\text { Supervisor developmental } \\
\text { feedback } \times \text { ingratiation }\end{array}$ & & & & & & & .01 \\
\hline$F$ & $8.23^{\star \star}$ & $36.05^{\star \star}$ & $17.87^{\star \star}$ & $18.24^{\star \star}$ & $4.45^{\star \star}$ & $5.41^{\star \star}$ & $4.95^{\star \star}$ \\
\hline$R^{2}$ & .06 & .27 & .12 & .16 & .03 & .08 & .09 \\
\hline$\Delta R^{2}$ & & $.21^{\star \star}$ & & $.04^{\star \star}$ & & $.05^{\star \star}$ & $.01^{\star \star}$ \\
\hline
\end{tabular}

Note: $N=399 ;{ }^{\star} p<.05,{ }^{\star \star} p<.01$.

We then used the PROCESS macro developed by Hayes (2013) to test the mediation and moderated mediation hypotheses. Following MacKinnon, Lockwood, and Williams (2004), all indirect and conditional indirect effects were tested based on 5,000 bootstrapping resamples. Hypothesis 3 proposed that the two social resources, including supervisor-focused expressive network resources and supervisor developmental feedback, accounted for mediating mechanisms through which political skill promoted career growth potential. As shown in Table 3, the indirect effect of political skill on career growth potential via (a) expressive network resources [indirect effect $=.08$, $\mathrm{SE}=.04,95 \%$ confidence interval $(\mathrm{CI})=.01-.16$ ] and $(\mathrm{b})$ developmental feedback [indirect effect $=.04, \mathrm{SE}=.02,95 \%$ confidence interval $(\mathrm{CI})=.01-.07]$ was positive and significant. Hence, Hypothesis 3 was supported.

We turn next to Hypothesis 4, which predicted that the strength of the indirect effect of political skill on career growth potential via (a) supervisor-focused expressive network resources and (b) supervisor developmental feedback would depend on the use of ingratiation. Specifically, Hypothesis 4 proposed the second-stage moderation such that the positive mediating relationship would grow stronger at higher levels of ingratiation. First, considering the interaction between expressive network resources and ingratiation in predicting career growth potential, we observed a statistically significant interaction term, but the direction of the moderating impact was rather negative $(\beta=-.14, p<.01)$ (see Table 2$)$, which contradicts our initial prediction. As shown in Figure 2, supervisor-focused expressive network resources were associated with career growth potential at low levels of ingratiation $(\beta=.21, p<.01)$ but not at high levels $(\beta=.02, p<.73)$. 
Table 3. Regression results for the indirect effect and conditional indirect effect of political skill on career growth potential through (a) supervisor-focused expressive network resources and (b) supervisor developmental feedback

\begin{tabular}{|c|c|c|c|c|}
\hline Indirect effects & Effect & SE & $\mathrm{LLCl}$ & ULCI \\
\hline \multicolumn{5}{|l|}{ Simple mediation } \\
\hline Total effect & .18 & .07 & .04 & .32 \\
\hline Direct effect & .06 & .08 & -.10 & .22 \\
\hline \multicolumn{5}{|c|}{ Supervisor-focused expressive network resources } \\
\hline Indirect effect & .08 & .04 & .01 & .16 \\
\hline \multicolumn{5}{|l|}{ Supervisor developmental feedback } \\
\hline Indirect effect & .04 & .02 & .01 & .07 \\
\hline \multicolumn{5}{|l|}{ Second-stage moderated mediation } \\
\hline \multicolumn{5}{|c|}{ Supervisor-focused expressive network resources } \\
\hline Simple paths for low ingratiation & .17 & .04 & .08 & .26 \\
\hline Simple paths for high ingratiation & .01 & .04 & -.07 & .10 \\
\hline Index of moderated mediation & Index $=-.08$ & .02 & -.12 & -.03 \\
\hline
\end{tabular}

Note: $N=$ 399. Bootstrap sample size $=5,000 . \mathrm{SE}=$ standard error; $\mathrm{LLCl}=$ lower limit confidence interval; $\mathrm{ULCl}=$ upper limit confidence interval.

Figure 2. The interactive association between supervisor-focused expressive network resources and ingratiation in predicting career growth potential.

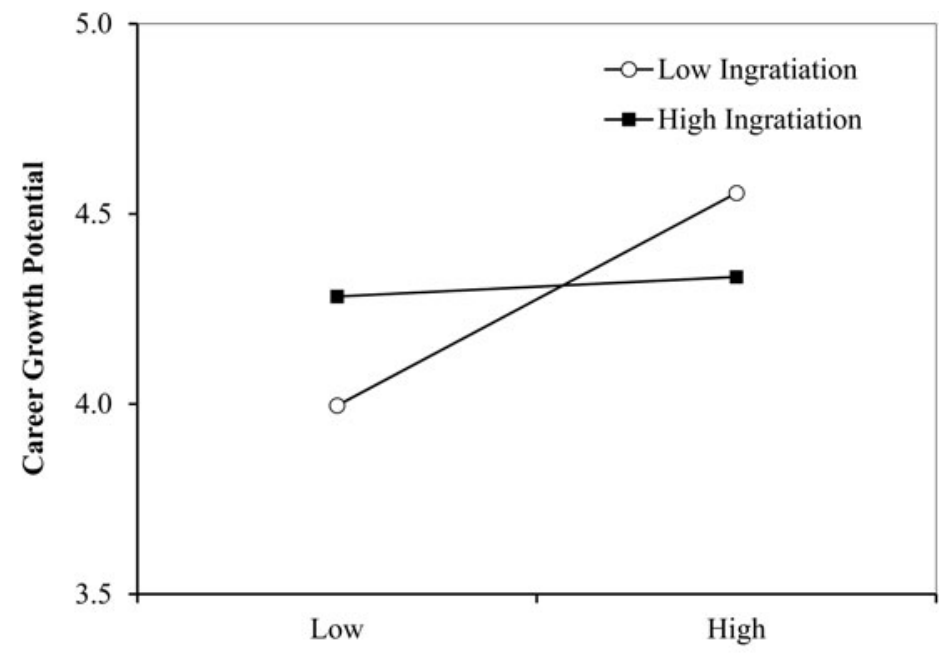

Supervisor-Focused Expressive Network Resources

Similarly, the conditional indirect effect of political skill on career growth potential strengthened at low levels of ingratiation (indirect effect $=.17, \mathrm{SE}=.04,95 \% \mathrm{CI}=.08-.26$ ) but became nonsignificant at high levels of ingratiation (indirect effect $=.01, \mathrm{SE}=.04,95 \% \mathrm{CI}=-.07$ to .10 ). Turning next to the interaction between supervisor developmental feedback and ingratiation in predicting career growth potential, we did not observe a statistically significant interaction term for this proposed relationship $(\beta=.01, p=81)$ (see Table 2$)$. Hence, the corresponding conditional indirect effect was no longer estimated. In sum, we can conclude that Hypothesis 4 was not empirically supported. The moderated mediation results are summarized in Table 3. The implications of these results are discussed further in the text. 


\section{Discussion}

This study employs the Japanese work context to explicate the link between political skill and career growth potential. One major rationale for choosing this context is that career progression among Japanese employees is closely linked to the quality of networks they have developed with others who are significant to their work life (Erez, 1992). According to social resources theory (Lin et al., 1981), relationship building precedes the acquisition of resources that are instrumental to achieving personal goals. Through active networking and their ability to be convincing, employees high in political skill are better able to secure the support, feedback, and information needed for their career growth. Correspondingly, our findings revealed that exercising political skill resulted in greater access to social resources, notably supervisor-focused expressive network resources and supervisor developmental feedback, both of which further enhanced employee career growth potential. Furthermore, although our results revealed that ingratiation operated meaningfully as a second-stage boundary condition in the proposed research model, the way it affected the utilization of the social resources obtained from having exercised political skill contradicts our initial prediction. Specifically, while supervisor-focused expressive network resources were positively associated with career growth potential when employees exercised ingratiation less frequently, the moderating impact of ingratiation was nonsignificant for supervisor developmental feedback. One common theme from these results is that once individuals have developed close interpersonal relationships with their supervisors and got access to the resources needed for career growth, resorting to using ingratiation becomes insignificant. Both theoretical and practical implications for the obtained results are discussed further in the text.

\section{Theoretical implications}

This study provides important implications for the career growth literature. First, the development of our proposed model is informed by the contemporary career circumstances facing Japanese employees. As noted by Weng and Zhu (2020) in their review paper, research on career growth should take a more context-specific approach because career growth is inevitably influenced by the context in which it occurs, such as economic situations, cultural backgrounds, etc. While Japanese firms were once known for offering lifelong employment for their employees, many companies now struggle to offer the same support since the collapse of the 'bubble' economy in the late 1990s (Kuroda \& Yamamoto, 2005). Given the new situation, many employees now realize the importance of developing and managing their own careers (Taniguchi et al., 2006). In this regard, we highlight political skill as an important interpersonal competency that individuals can draw on to exert control over their career course. Using social resources theory (Lin et al., 1981), relationship building enables individuals' access to support, organizational information, and feedback on work-related issues from their supervisors, further promoting their career growth potential. Due to key qualities such as social astuteness and networking ability, political skill can explain why some employees are adept in recognizing opportunities from building strong relationships with their supervisors. In addition, due to key qualities such as interpersonal influence and apparent sincerity, political skill helps explain how individuals can effectively engage in interpersonal interactions with their supervisors (McAllister et al., 2018). In support of this, our results revealed that political skill predicted employees' access to social resources, notably supervisor-focused expressive network resources and supervisor developmental feedback.

Second, for a more fine-grained understanding of which social resources would be instrumental to achieving career growth in the Japanese work context, our proposed model is further informed by its dominant cultural features, notably high collectivism and high uncertainty avoidance (Hofstede, 1984). In a highly collectivistic culture, people strongly value group membership, which further explains the tendency of individuals to engage in interpersonal relationships. In a high uncertainty avoidance culture, people tend to feel uneasy in ambiguous situations, which explains the propensity of individuals to build relationships with more senior staff, such as 
their supervisors, since these people can offer important information that helps reduce uncertainty about the organizational environment (Bozionelos, 2006; Hofstede, 2001). Given the interpersonal focus of the Japanese work culture, we cast a spotlight on resources that are interpersonally sought from the employee's supervisor, including supervisor-focused expressive network resources and supervisor developmental feedback. As informed by social resources theory (Lin et al., 1981), the nature of the resources obtained from relationship building is important in achieving personal objectives. Accordingly, our results revealed that expressive network resources and developmental feedback from supervisors accounted for mediating mechanisms through which political skill predicted career growth potential.

Importantly, the question 'why do some employees experience more successful career mobility?' still requires further explanation and empirical support (Weng \& Zhu, 2020). Given that career growth is a form of upward movement in an organization, our study enables a better understanding of how expressive network resources and developmental feedback from supervisors can aid career growth. Thus far, the research has largely underscored the role of instrumental network resources, which serve functions such as exposure to top management, professional advice, and access to job-related information, in obtaining extrinsic career outcomes (Bozionelos, 2003; Peng \& Luo, 2000). In contrast, because the primary function of expressive network resources is to provide friendship and emotional support (Bozionelos, 2003), there is rather limited research done to uncover their potential in promoting employees' career mobility (e.g., Chen, Chang, \& Chiang, 2017). Our argument is that expressive network resources consist of strong connections among organizational members, which foster trust and cooperation, thereby facilitating an exchange of valued resources that can enhance one's career growth potential (Brass, 1984). A similar pattern can be observed for supervisor developmental feedback. To the best of our understanding, research has thus far determined the work-related behaviors of developmental feedback, including task performance, helping behaviors and creative behaviors (Li et al., 2011; Zhou, 2003). Due to the future-oriented nature of the developmental feedback that is aimed toward improving one's performance and other aspects of their work life (George \& Zhou, 2007), it should be highly useful in promoting longer-term outcomes, such as career growth. Our study provides empirical support for the instrumental role that both supervisor-focused expressive network resources and supervisor developmental feedback can serve in promoting one's career growth potential.

Finally, although the acquired results did not support our initial prediction pertaining to the moderating impact of ingratiation, we obtained unique insight into exactly how ingratiation intervenes in the proposed relationship among political skill, expressive network resources and developmental feedback from supervisors, and career growth potential. That is, as employees have already developed favorable connections with their supervisors and subsequently accessed the necessary resources for career growth, exercising ingratiation toward the supervisors would not help them leverage the available resources. For supervisor-focused expressive network resources in particular, our results suggest that employees would be better off if they exercised ingratiation less frequently. To explain this contradictory result, we draw on weak tie theory (Granovetter, 1973) to offer an alternative perspective. The theory argues that relationship ties that employees develop with others can vary in strength. Strong ties can be described as closely-knitted relationships that are emotionally intense, have frequent contact, and involve multiple relationship types (Uzzi, 1996). By contrast, weak ties can be described as not emotionally intense, having infrequent contact, and restricted to one narrow type of relationship (e.g., an acquaintance). While the key advantage of having strong ties is quick access to a greater amount of resources, the key advantage of having weak ties is access to rather unique resources (Granovetter, 1973). Hence, when employees use ingratiation with someone whom they have already shared a strong tie, they may gain more of the same resources but no further unique resources that could create additional opportunities for career advancement. Strong ties tend to offer similar information and benefits because people within these relationships likely share similar social networks, which 
rather constrain their access to a variety of other resources (Seibert et al., 2001). Therefore, given that employees have already formed genuine relationships with their supervisors, using ingratiation to make oneself appear more likable is deemed insignificant.

Adding to the fact that employees have already formed genuine favorable relationships with their supervisors, an attempt to further engage ingratiation may instead be perceived as lacking genuineness and holding ulterior motives (Liu, Ferris, Xu, Weitz, \& Perrewé, 2014). Hence, while ingratiation may be exercised to enhance an individual's likeability in the eyes of others, ingratiation may as well backfire those who engage in the behavior if the tactic is not enacted in the right context, such as in a situation where strong interpersonal connections have already been established between employees and supervisors. Indeed, the success of ingratiation depends largely on the social context in which the tactic is used, which will have further impact on the extent to which personal motives underlying ingratiation can be detected (Jones \& Pittman, 1982; Liu et al., 2014). This further explains why we did not receive empirical support for our hypothesized positive moderating impact of ingratiation.

\section{Practical implications}

This study provides important practical implications geared toward individual employees, supervisors, and organizations, especially those who face somewhat similar work and career circumstances as in Japan. First, due to the dynamics of the current business environment, characterized by high competition and uncertainty, Japanese firms can no longer guarantee lifelong employment for their employees. In this regard, many people have now realized the importance of taking charge of their own careers (Taniguchi et al., 2006). As reflected in our findings, employees can benefit from using their political skill. Unlike innate demographic characteristics and personality traits, political skill can be learned and developed over time (Ferris et al., 2007). Employees can acquire this political savvy while at work. For instance, to sharpen their social astuteness, employees may take time to observe their surrounding work environment, understand its boundaries, and learn who the key players are in the organization. To master their interpersonal influence and networking ability, employees may become more active in taking part in professional social events organized by their employer and outside institutions. Organizations may offer training and opportunities that enable employees to practice interpersonal strategies associated with political skill, such as networking (Kacmar, Andrews, Harris, \& Tepper, 2013).

Second, because our proposed model is informed by some dominant features of the Japanese work culture, notably the work culture being highly collectivistic and high uncertainty avoidance (Hofstede, 1984), the obtained results should particularly pertain to employees working in organizations that exhibit somewhat similar cultural values. Informed by these cultural characteristics, we emphasize relationship building as an important element in achieving career growth (Bozionelos, 2006; Hofstede, 2001). Given the value of the benefits embedded in supervisorfocused expressive network resources and supervisor developmental feedback, the extent to which employees will attain these resources may vary according to how close and favorable their relationships with their supervisors are. Nevertheless, it is important for organizations to recognize the relevance of making these resources, such as work confirmation, feedback related to work-life aspects, and important organizational information, available to everyone. If such support is lacking, employers may risk losing talent (Weng et al., 2010). Hence, organizations may consider how they can give employees greater access to such support through work practices, such as mentoring, performance appraisal interviews, and career counseling services.

Our results also provide important caution for employees who attempt to further leverage the strong interpersonal relationships they have developed with their supervisors and the benefits embedded in these social ties. Specifically, using ingratiation with people whom employees are already closely connected is deemed ineffective. Once again, guided by weak tie theory (Granovetter, 1973), we suggest that employees may instead consider how they can make use of ingratiation to 
build connections with other organizational members or even outside professionals whom they have not yet formed a strong tie. The key advantage of having weak ties is that people whom employees only know as acquaintances may be able to offer unique resources that they do not currently possess (Seibert et al., 2001). Such strategy of gearing toward developing ties with acquaintances outside the current professional circle should be particularly appealing to younger Japanese employees who seek to obtain career growth opportunities not only from their current employer but also from future organizations that they can potentially become a part of (Taniguchi et al., 2006). Career growth opportunities that individuals can obtain from new employers include more challenging assignments and promotions. Therefore, it is no longer taken for granted that employees will remain with one single organization throughout their career (Takase, Teraoka, \& Yabase, 2016; Yanadori \& Kato, 2007). This is another reminder for organizations to ensure the accessibility and availability of career growth opportunities to their employees, such as job enrichment, training and development, and promotion opportunities, if they wish to retain their talents rather than to incur more costs for having to recruit new people.

\section{Limitations and future research directions}

However, this study also presents some limitations, which should be carefully considered when interpreting its results. First, we acknowledge the limitation of the career growth measure adopted in this study, which can only be used to infer employees' potential for career growth, not their actual growth. To capture an individual's career growth experience more thoroughly, future studies may consider adopting both objective and subjective measures of career-related outcomes. Examples of objective measures include the actual number of promotions, training programs, and other development opportunities one has obtained during their employment with the current organization (Ng, Eby, Sorensen, \& Feldman, 2005). Subjective measures may include promotability ratings (i.e., the likelihood of being promoted to a higher organizational level) and career satisfaction (i.e., employees' subjective evaluations of their accomplishments of personal career goals) (London \& Stumpf, 1982).

Second, our data were obtained from companies operating in the manufacturing industry in Japan using a convenience sampling approach. Therefore, the empirical evidence shown in this study may not apply to other industries and cultural contexts. To generalize the study's results, future research may consider replicating these findings in different industries as well as in different cultural settings. Third, while we engaged with participants from various organizational levels, such as line management, middle management, and top management, we did not control for how employees' positional levels may affect our proposed relationships. For instance, Podolny and Baron (1997) argued that organizational ranks may influence the acquisition of resources and subsequent career advancement. However, our control of organizational tenure as one form of an individual's seniority and experience within an organization is also noteworthy. Indeed, research revealed that tenure can have either a positive or negative impact on employee career progression (Bowman, 1964; McClelland et al., 2012; Thacker \& Wayne, 1995).

Finally, future research may build on this study by uncovering other potential mediating mechanisms through which employees high in political skill can increase their chances for career growth. Substantial research examines the moderating role of political skill, specifically its impact on the effectiveness of various social influence tactics, such as ingratiation, self-promotion, and rationality (Harris, Kacmar, Zivnuska, \& Shaw, 2007; Kolodinsky, Treadway, \& Ferris, 2007; Treadway et al., 2013). However, what is currently lacking is a better understanding of how using political skill may translate into one's choice of specific influence strategies. That is, how do employees who are high in political skill go about achieving career growth through the exercise of social influence? Although the moderating role of ingratiation appears to be rather nonsignificant in our study, it may infer 'how' such a social influence tactic should play out in the research model, for instance, as a mediating mechanism that explicates the link between political skill and 
career growth potential. In fact, various social influence tactics have been increasingly recognized as effective career strategies, including ingratiation, self-promotion, and exemplification (King, 2004; Sibunruang et al., 2016).

\section{Conclusion}

In conclusion, our results provide an integrated understanding of how interpersonal competency (i.e., political skill), social resources (i.e., supervisor-focused expressive network resources and supervisor developmental feedback), strategic interpersonal behaviors (i.e., ingratiation), and career outcomes (i.e., career growth) play out as informed by the Japanese work context. Moreover, this study unfolds the potential of the expressive network resources and developmental feedback sourced from supervisors in achieving extrinsic career outcomes, notably career growth potential.

\section{References}

Aryee, S., Wyatt, T., \& Stone, R. (1996). Early career outcomes of graduate employees: The effect of mentoring and ingratiation. Journal of Management Studies, 33(1), 95-118. doi: 10.1111/j.1467-6486.1996.tb00800.x

Blickle, G., Kramer, J., Schneider, P. B., Meurs, J. A., Ferris, G. R., Mierke, J., ... Momm, T. D. (2011). Role of political skill in job performance prediction beyond general mental ability and personality in cross-sectional and predictive studies. Journal of Applied Social Psychology, 41(2), 488-514. doi: 10.1111/j.1559-1816.2010.00723.x

Blickle, G., Schneider, P. B., Liu, Y., \& Ferris, G. R. (2011). A predictive investigation of reputation as mediator of the political-skill/career-success relationship. Journal of Applied Social Psychology, 41(12), 3026-3048. doi: 10.1111/ j.1559-1816.2011.00862.x

Blommaert, L., Meuleman, R., Leenheer, S., \& Butkēviča, A. (2020). The gender gap in job authority: Do social network resources matter? Acta Sociologica, 63(4), 381-399. doi: 10.1177/0001699319847504

Bolino, M. C., \& Turnley, W. H. (1999). Measuring impression management in organizations: A scale development based on the Jones and Pittman taxonomy. Organizational Research Methods, 2(2), 187-206. doi: 10.1177/109442819922005

Bowman, G. (1964). What helps or harms promotability? Harvard Business Review, 42(1), 184-196.

Bozionelos, N. (2003). Intra-organizational network resources: Relation to career success and personality. The International Journal of Organizational Analysis, 11(1), 41-66. doi: 10.1108/eb028962

Bozionelos, N. (2006). Mentoring and expressive network resources: Their relationship with career success and emotional exhaustion among Hellenes employees involved in emotion work. The International Journal of Human Resource Management, 17(2), 362-378. doi: 10.1080/09585190500405009

Bozionelos, N., \& Wang, L. (2006). The relationship of mentoring and network resources with career success in the Chinese organizational environment. The International Journal of Human Resource Management, 17(9), 1531-1546. doi: 10.1080/ 09585190600878345

Bradach, J. L., \& Eccles, R. G. (1989). Price, authority, and trust: From ideal types to plural forms. Annual Review of Sociology, 15, 97-118, Retrieved from https://www.jstor.org/stable/2083220.

Brass, D. J. (1984). Being in the right place: A structural analysis of individual influence in an organization. Administrative Science Quarterly, 29(4), 518-539. doi: 10.2307/2392937

Chen, M. H., Chang, Y. Y., \& Chiang, M. T. (2017). Human capital and career success of creative entrepreneurs: Is guanxi network a missing link? Journal of Small Business \& Entrepreneurship, 29(4), 313-331. doi: 10.1080/ 08276331.2017.1300849

Chiesa, R., Van der Heijden, B. I., Mazzetti, G., Mariani, M. G., \& Guglielmi, D. (2020). "It is all in the game!": The role of political skill for perceived employability enhancement. Journal of Career Development, 47(4), 394-407. doi: 10.1177/ 0894845319832666

Cullen, K. L., Gerbasi, A., \& Chrobot-Mason, D. (2018). Thriving in central network positions: The role of political skill. Journal of Management, 44(2), 682-706. doi: 10.1177/0149206315571154

Dore, R. P. (1973). British factory-Japanese factory: The origins of national diversity in industrial relations, with a new afterword. World Development, 2(10-12), 73-79. doi: 10.1016/0305-750X(74)90057-6

Epitropaki, O., Kapoutsis, I., Ellen III B. P., Ferris, G. R., Drivas, K., \& Ntotsi, A. (2016). Navigating uneven terrain: The roles of political skill and LMX differentiation in prediction of work relationship quality and work outcomes. Journal of Organizational Behavior, 37(7), 1078-1103. doi:10.1002/job.2100

Erez, M. (1992). Interpersonal communication systems in organizations, and their relationships to cultural values, productivity and innovation: The case of Japanese corporations. Applied Psychology: An International Review, 41(1), $43-64$.

Fang, R., Chi, L., Chen, M., \& Baron, R. A. (2015). Bringing political skill into social networks: Findings from a field study of entrepreneurs. Journal of Management Studies, 52(2), 175-212. doi: 10.1111/joms.12107 
Feldman, D. C. (1981). The multiple socialization of organization members. Academy of Management Review, 6(2), 309-318. doi: 10.1037/0021-9010.66.2.127

Ferris, G. R., \& Judge, T. A. (1991). Personnel/human resources management: A political influence perspective. Journal of Management, 17(2), 447-488. doi: 10.1177/014920639101700208

Ferris, G. R., Treadway, D. C., Kolodinsky, R. W., Hochwarter, W. A., Kacmar, C. J., Douglas, C., \& Frink, D. D. (2005). Development and validation of the political skill inventory. Journal of Management, 31(1), 126-152. doi: 10.1177/ 0149206304271386

Ferris, G. R., Treadway, D. C., Perrewé, P. L., Brouer, R. L., Douglas, C., \& Lux, S. (2007). Political skill in organizations. Journal of Management, 33(3), 290-320. doi: 10.1177/0149206307300813

Fombrun, C. J. (1982). Strategies for network research in organizations. Academy of Management Review, 7(2), 280-291. doi: 10.5465/amr.1982.4285594

George, J. M., \& Zhou, J. (2007). Dual tuning in a supportive context: Joint contributions of positive mood, negative mood, and supervisory behaviors to employee creativity. Academy of Management Journal, 50(3), 605-622. doi: 10.5465/ amj.2007.25525934

Granovetter, M. S. (1973). The strength of weak ties. American Journal of Sociology, 6, 1360-1380. doi: 10.1086/225469

Harris, K. J., Kacmar, K. M., Zivnuska, S., \& Shaw, J. D. (2007). The impact of political skill on impression management effectiveness. Journal of Applied psychology, 92(1), 278-285. doi: 10.1037/0021-9010.92.1.278

Hayes, A. F. (2013). Introduction to mediation, moderation, and conditional process analysis: A regression-based approach. New York: Guilford Press.

Heider, F. (1958). The psychology of interpersonal relations. New York: Wiley.

Higgins, C. A., \& Judge, T. A. (2004). The effect of applicant influence tactics on recruiter perceptions of fit and hiring recommendations: A field study. Journal of Applied Psychology, 89(4), 622. doi: 10.1037/0021-9010.89.4.622

Hofstede, G. (1984). Culture's consequences: International differences in work-related values (Vol. 5). Newbury Park: Sage publications.

Hofstede, G. (2001). Culture's consequences: Comparing values, behaviors, institutions and organizations across nations. Thousand Oaks: Sage publications.

Ibarra, H. (1993). Network centrality, power, and innovation involvement: Determinants of technical and administrative roles. Academy of Management Journal, 36(3), 471-501. doi: 10.5465/256589

Jones, E. E., \& Pittman, T. S. (1982). Toward a general theory of strategic self-presentation. In J. Suls (Ed.), Psychological perspective on the self (pp. 231-261). Hillsdale, NJ: Erlbaum

Joo, B. K. B., \& Park, S. (2010). Career satisfaction, organizational commitment, and turnover intention. Leadership \& Organization Development Journal, 31(6), 482-500. doi: 10.1108/01437731011069999

Judge, T. A., \& Bretz Jr R. D. (1994). Political influence behavior and career success. Journal of Management, 20(1), 43-65.

Kacmar, K. M., Andrews, M. C., Harris, K. J., \& Tepper, B. J. (2013). Ethical leadership and subordinate outcomes: The mediating role of organizational politics and the moderating role of political skill. Journal of Business Ethics, 115(1), 33-44. doi: $10.1007 /$ s10551-012-1373-8

King, Z. (2004). Career self-management: Its nature, causes and consequences. Journal of Vocational Behavior, 65(1), 112-133. doi: 10.1016/S0001-8791(03)00052-6

Kline, P. (1999). Handbook of psychological testing. London: Routledge.

Kolodinsky, R. W., Treadway, D. C., \& Ferris, G. R. (2007). Political skill and influence effectiveness: Testing portions of an expanded Ferris and Judge (1991) model. Human Relations, 60(12), 1747-1777. doi: 10.1177/0018726707084913

Krackhardt, D. (1992). The strength of strong ties: The importance of philos in organizations. In R. Eccles \& N. Nohria (Eds.), Networks and organizations: Structure, form and action (pp. 216-239). Boston: Harvard Business School Press.

Kumar, K., \& Beyerlein, M. (1991). Construction and validation of an instrument for measuring ingratiatory behaviors in organizational settings. Journal of Applied Psychology, 76(5), 619-627. doi: 10.1037/0021-9010.76.5.619

Kuroda, S., \& Yamamoto, I. (2005). Wage fluctuations in Japan after the bursting of the bubble economy: Downward nominal wage rigidity, payroll, and the unemployment rate. Institute for Monetary and Economic Studies, Bank of Japan.

Leung, K., Au, Y. F., Fernández-Dols, J. M., \& Iwawaki, S. (1992). Preference for methods of conflict processing in two collectivist cultures. International Journal of Psychology, 27(2), 195-209. doi: 10.1080/00207599208246875

Li, N., Harris, T. B., Boswell, W. R., \& Xie, Z. (2011). The role of organizational insiders' developmental feedback and proactive personality on newcomers' performance: An interactionist perspective. Journal of Applied Psychology, 96(6), 1317-1327. doi: 10.1037/a0024029

Liden, R. C., \& Mitchell, T. R. (1988). Ingratiatory behaviors in organizational settings. Academy of Management Review, 13(4), 572-587. doi: 10.5465/amr.1988.4307430

Lin, N., Ensel, W. M., \& Vaughn, J. C. (1981). Social resources and strength of ties: Structural factors in occupational status attainment. American Sociological Review, 46(4), 393-405. doi: 10.2307/2095260

Liu, Y., Ferris, G. R., Xu, J., Weitz, B. A., \& Perrewé, P. L. (2014). When ingratiation backfires: The role of political skill in the ingratiation-internship performance relationship. Academy of Management Learning and Education, 13(4), 569-586. doi: 10.5465/amle.2012.0399 
Liu, Y., Liu, J., \& Wu, L. (2010). Are you willing and able? Roles of motivation, power, and politics in career growth. Journal of Management, 36(6), 1432-1460. doi: 10.1177/0149206309359810

London, M., \& Stumpf, S. A. (1982). Managing careers. Boston, MA: Addison-Wesley.

MacKinnon, D. P., Lockwood, C. M., \& Williams, J. (2004). Confidence limits for the indirect effect: Distribution of the product and resampling methods. Multivariate Behavioral Research, 39(1), 99-128. doi: 10.1207/s15327906mbr3901_4

McAllister, C. P., Ellen III B. P., \& Ferris, G. R. (2018). Social influence opportunity recognition, evaluation, and capitalization: Increased theoretical specification through political skill's dimensional dynamics. Journal of Management, 44(5), 1926-1952. doi:10.1177/0149206316633747

McClelland, P. L., Barker III V. L., \& Oh, W. Y. (2012). CEO Career horizon and tenure: Future performance implications under different contingencies. Journal of Business Research, 65(9), 1387-1393. doi:10.1016/j.jbusres.2011.09.003

Munyon, T. P., Summers, J. K., Thompson, K. M., \& Ferris, G. R. (2015). Political skill and work outcomes: A theoretical extension, meta-analytic investigation, and agenda for the future. Personnel Psychology, 68(1), 143-184. doi: 10.1111/peps.12066

Ng, T. W., Eby, L. T., Sorensen, K. L., \& Feldman, D. C. (2005). Predictors of objective and subjective career success: A meta-analysis. Personnel Psychology, 58(2), 367-408. doi: 10.1111/j.1744-6570.2005.00515.x

Nunnally, J. C. (1978). Psychometric theory (2nd ed.). New York: McGraw-Hill.

Peng, M. W., \& Luo, Y. (2000). Managerial ties and firm performance in a transition economy: The nature of a micro-macro link. Academy of Management Journal, 43(3), 486-501. doi: 10.5465/1556406

Perrewé, P. L., Ferris, G. R., Frink, D. D., \& Anthony, W. P. (2000). Political skill: An antidote for workplace stressors. Academy of Management Perspectives, 14(3), 115-123. doi: 10.5465/ame.2000.4468071

Perrewe, P. L., \& Nelson, D. L. (2004). Gender and career success: The facilitative role of political skill. Organizational Dynamics, 33(4), 366-378. doi: 10.1016/j.orgdyn.2004.09.004

Podolny, J. M., \& Baron, J. N. (1997). Resources and relationships: Social networks and mobility in the workplace. American Sociological Review, 62(5), 673-693. doi: 10.2307/2657354

Porter, C. M., \& Woo, S. E. (2015). Untangling the networking phenomenon: A dynamic psychological perspective on how and why people network. Journal of Management, 41(5), 1477-1500. doi: 10.1177/0149206315582247

Ren, S., \& Chadee, D. (2017). Influence of work pressure on proactive skill development in China: The role of career networking behavior and Guanxi HRM. Journal of Vocational Behavior, 98, 152-162. doi: 10.1016/j.jvb.2016.11.004

Seibert, S. E., Kraimer, M. L., \& Liden, R. C. (2001). A social capital theory of career success. Academy of Management Journal, 44(2), 219-237. doi: 10.5465/3069452

Seibert, S. E., Sargent, L. D., Kraimer, M. L., \& Kiazad, K. (2017). Linking developmental experiences to leader effectiveness and promotability: The mediating role of leadership self-efficacy and mentor network. Personnel Psychology, 70(2), 357-397. doi: 10.1111 peps.12145

Sibunruang, H., Garcia, P. R. J. M., \& Tolentino, L. R. (2016). Ingratiation as an adapting strategy: Its relationship with career adaptability, career sponsorship, and promotability. Journal of Vocational Behavior, 92, 135-144. doi: 10.1016/ j.jvb.2015.11.011

Spurk, D., Kauffeld, S., Barthauer, L., \& Heinemann, N. S. (2015). Fostering networking behavior, career planning and optimism, and subjective career success: An intervention study. Journal of Vocational Behavior, 87, 134-144. doi: 10.1016/ j.jvb.2014.12.007

Stroh, L. K., Brett, J. M., \& Reilly, A. H. (1992). All the right stuff: A comparison of female and male managers' career progression. Journal of Applied Psychology, 77(3), 251-260. doi: 10.1037/0021-9010.77.3.251

Takase, M., Teraoka, S., \& Yabase, K. (2016). Retaining the nursing workforce: Factors contributing to the reduction of nurses' turnover intention in Japan. Journal of Nursing Management, 24(1), 21-29. doi: 10.1111/jonm.12266

Taniguchi, M., Kato, I., \& Suzuki, R. (2006). Career 'mist,' 'hope,' and 'drift': Conceptual framework for understanding career development in Japan. Career Development International, 11(30), 265-276. doi: 10.1108/13620430610661777

Thacker, R. A., \& Wayne, S. J. (1995). An examination of the relationship between upward influence tactics and assessments of promotability. Journal of Management, 21(4), 739-756. doi: 10.1177/014920639502100408

Todd, S. Y., Harris, K. J., Harris, R. B., \& Wheeler, A. R. (2009). Career success implications of political skill. The Journal of Social Psychology, 149(3), 279-304. doi: 10.3200/SOCP.149.3.279-304

Treadway, D. C., Breland, J. W., Williams, L. M., Cho, J., Yang, J., \& Ferris, G. R. (2013). Social influence and interpersonal power in organizations: Roles of performance and political skill in two studies. Journal of Management, 39(6), $1529-1553$. doi: $10.1177 / 0149206311410887$

Uzzi, B. (1996). The sources and consequences of embeddedness for the economic performance of organizations: The network effect. American Sociological Review, 61(4), 674-698. doi: 10.2307/2096399

Wei, L. Q., Chiang, F. F., \& Wu, L. Z. (2012). Developing and utilizing network resources: Roles of political skill. Journal of Management Studies, 49(2), 381-402. doi: 10.1111/j.1467-6486.2010.00987.x

Wei, L. Q., Liu, J., Chen, Y. Y., \& Wu, L. Z. (2010). Political skill, supervisor-subordinate guanxi and career prospects in Chinese firms. Journal of Management Studies, 47(3), 437-454. doi: 10.1111/j.1467-6486.2009.00871.x

Weng, Q., McElroy, J. C., Morrow, P. C., \& Liu, R. (2010). The relationship between career growth and organizational commitment. Journal of Vocational Behavior, 77(3), 391-400. doi: 10.1016/j.jvb.2010.05.003 
Weng, Q., \& Zhu, L. (2020). Individuals' career growth within and across organizations: A review and agenda for future research. Journal of Career Development, 47(3), 239-248. doi: 10.1177/0894845320921951

Westphal, J. D., \& Shani, G. (2016). Psyched-up to suck-up: Self-regulated cognition, interpersonal influence, and recommendations for board appointments in the corporate elite. Academy of Management Journal, 59(2), 479-509. doi: 10.5465/ amj.2014.0010

Westphal, J. D., \& Stern, I. (2007). Flattery will get you everywhere (especially if you are a male Caucasian): How ingratiation, boardroom behavior, and demographic minority status affect additional board appointments at US companies. Academy of Management Journal, 50(2), 267-288. doi: 10.5465/amj.2007.24634434

Wolff, H. G., \& Moser, K. (2009). Effects of networking on career success: A longitudinal study. Journal of Applied Psychology, 94(1), 196-206. doi: 10.1037/a0013350

Wu, L. Z., Kwan, H. K., Wei, L. Q., \& Liu, J. (2013). Ingratiation in the workplace: The role of subordinate and supervisor political skill. Journal of Management Studies, 50(6), 991-1017. doi: 10.1111/joms.12033

Yanadori, Y., \& Kato, T. (2007). Average employee tenure, voluntary turnover ratio, and labor productivity: Evidence from Japanese firms. The International Journal of Human Resource Management, 18(10), 1841-1857. doi: 10.1080/ 09585190701570981

Yang, J., Liu, C., Wang, C., \& Zhang, Q. (2020). How gender and political will affect employees' social network embeddedness. Psychological Reports, 123(6), 2519-2537. doi: 10.1159/000507639

Zhou, J. (2003). When the presence of creative coworkers is related to creativity: Role of supervisor close monitoring, developmental feedback, and creative personality. Journal of Applied Psychology, 88(3), 413-422. doi: 10.1037/ 0021-9010.88.3.413

Hataya is a Senior Lecturer in Human Resource Management at the University of Waikato, New Zealand. She received her $\mathrm{PhD}$ in Management (Organizational Behaviour) from the Australian National University. Hataya is a research active faculty with publications in international outlets, such as Journal of Vocational Behavior, Journal of Career Assessment, and Handbook of Organizational Politics (2nd Edition).

Norifumi Kawai is an Associate Professor in Global Strategy in the Faculty of Economics at Sophia University, Japan. He holds a $\mathrm{PhD}$ in Managerial Economics from the Mercator School of Management at the Universität Duisburg-Essen, Germany. His articles have been published in Asian Business \& Management, British Journal of Management, European Journal of International Management, Global Economic Review, International Business Review, International Journal of Gender \& Entrepreneurship, International Journal of Human Resource Management, Journal of Small Business \& Enterprise Development, and Journal of World Business.

Cite this article: Sibunruang H, Kawai N (2023). Promoting career growth potential: political skill, the acquisition of social resources and ingratiation. Journal of Management \& Organization 29, 227-246. https://doi.org/10.1017/jmo.2021.25 